\title{
Primary CNS teratocarcinoma
}

\author{
Danilo Vitorovic ${ }^{1}$, Jordan Rosenblum ${ }^{2}$, Chinnamma Thomas ${ }^{3}$, John Lee $^{3}$ and José Biller ${ }^{1 *}$ \\ 1 Department of Neurology, Stritch School of Medicine, Loyola University Chicago, Maywood, IL, USA \\ 2 Section of Neuroradiology, Department of Radiology, Stritch School of Medicine, Loyola University Chicago, Maywood, IL, USA \\ ${ }^{3}$ Department of Pathology, Stritch School of Medicine, Loyola University Chicago, Maywood, IL, USA
}

Edited by:

John McNulty, Loyola University

Chicago, USA

Reviewed by:

Luciano A. Sposato, INECO

Foundation, Argentina

Emilia Gatto, Sanatorio de la Trinidad

Mitre, Argentina

${ }^{*}$ Correspondence:

José Biller, Department of Neurology,

Stritch School of Medicine, Loyola

University Chicago, 2160 South 1st

Avenue, Maywood, IL 60153, USA.

e-mail: jbiller@lumc.edu
Primary central nervous system (CNS) teratomas are rare tumors that consist of all three germ cell layers. We describe a young man with a primary malignant CNS teratocarcinoma presenting as leptomeningeal carcinomatosis. Diagnosis of primary CNS teratocarcinomas is challenging; relentless pursuit of the diagnosis must follow even if early ancillary studies are inconclusive.

Keywords: teratocarcinoma, leptomeningeal malignancy, central nervous system

\section{INTRODUCTION}

Teratomas are tumors composed of tissues originating from all three germ cell layers (Kumar et al., 2005). Primary central nervous system (CNS) teratomas are rare, and can manifest as an intracranial and/or spinal lesions (Smoker et al., 1986; Agrawal et al., 2010). Primary CNS teratomas, similar to other germ cell tumors, usually arise in midline structures (Schild et al., 1996; Kumar et al., 2005). A higher prevalence of these tumors is observed in the Far East (Jennings et al., 1985; Suh et al., 2002). These tumors occur mostly in the first and second decade of life, although age distribution from birth to the sixth decade of life has been reported (Ho and Liu, 1990; Agrawal et al., 2010).

Teratomas are classified as mature, immature, or teratomas with malignant transformation (Love et al., 2008). Mature teratomas have fully differentiated ectodermal, mesodermal, and endodermal tissues. Presence of undifferentiated tissues resembling fetal tissues defines teratoma as immature. Malignant transformation of teratoma include squamous cell carcinoma (Matsutani et al., 1997), adenocarcinoma (Freilich et al., 1995), rhabdomyosarcoma (Bjornsson et al., 1985), leiomyosarcoma (Skullerud et al., 1995), and erythroleukemia (Heimdal et al., 1991) among others.

Clinical presentation depends on tumor location. Common presenting symptoms are headaches, visual disturbances, and other manifestations of raised intracranial pressure (ICP; Ropper and Samuels, 2009). Definitive diagnosis requires histopathological confirmation.

We are reporting a case of a young man with primary teratocarcinoma disseminated to the posterior fossa and spinal leptomeninges.

\section{CASE}

A 37-year-old man presented to another institution with generalized headaches associated with nausea and vomiting. He had no photophobia or phonophobia, double or blurred vision, limb weakness, or numbness. He drank an average of $6 \mathrm{~L}$ of water daily and had marked polyuria.

Magnetic resonance imaging (MRI) of the brain with and without contrast was unremarkable. Initial cerebrospinal fluid (CSF) analysis was normal (Table 1). Three months after onset of symptoms, he had worsening headaches along with posterior neck pain and vomiting. He was admitted to his local hospital. Unenhanced computed tomography (CT) showed hydrocephalus. ICP was $28 \mathrm{~cm}$ of CSF. An emergent external ventricular drain (EVD) was placed. CSF analysis from the EVD was unremarkable (Table 1). His headaches improved and a ventriculo-peritoneal (VP) shunt was placed the following day. A supratentorial convexity dural and leptomeningeal biopsy was done, but no definitive diagnosis was reached.

A few months later his symptoms recurred. He again had severe, generalized headaches, recurrent vomiting, and binocular horizontal diplopia. CT head without contrast showed the VP shunt in proper place (Figure 1). CSF showed a protein content of $1217 \mathrm{mg} / \mathrm{mL}$. CSF glucose was undetectable. Rheumatology consult suggested a possible autoimmune disorder, since he had positive ANA and SS-B antibodies. However, SS-A, Jo-1 antibody, anti-protease 3 , anti-myeloperoxidase, Smith antibody, RNP antibody, SM/RNP antibody, Scl-70, dsDNA antibody, ribosomal P Protein antibody, chromatin antibody, and anti-centromere antibody were unremarkable. CT chest/abdomen/pelvis with and without contrast showed a right kidney simple cyst and no adrenal masses.

Two months later, 10 months after initial presentation, he again complained of headaches, vomiting, and horizontal binocular diplopia. MRI showed findings suggestive of communicating hydrocephalus (Figure 2). A CSF protein content of $491 \mathrm{mg} / \mathrm{mL}$ and a CSF glucose of $66 \mathrm{mg} / \mathrm{mL}$ were noted this time (Table 1). He had revision of the VP shunt and another shunt was placed, this time in the fourth ventricle. He also received dexamethasone. 
Table 1 | Temporal profile of CSF analysis.

\begin{tabular}{|c|c|c|c|c|c|}
\hline Time & June 2010 & September 2010 & March 2011 & May 2011 & June 2011 \\
\hline Opening pressure & Not recorded & $28 \mathrm{~cm} \mathrm{CSF}$ & Not recorded & Not recorded & Not recorded \\
\hline Color & Colorless & Colorless & Xanthochromic & Xanthochromic & Xanthochromic \\
\hline WBCs & $2 / \mathrm{mm}^{3}$ & $1 / \mathrm{mm}^{3}$ & $11 / \mathrm{mm}^{3}$ & $1 / \mathrm{mm}^{3}$ & $4 / \mathrm{mm}^{3}$ \\
\hline RBCs & $102 / \mathrm{mm}^{3}$ & $601 / \mathrm{mm}^{3}$ & $31 / \mathrm{mm}^{3}$ & $313 / \mathrm{mm}^{3}$ & $3025 / \mathrm{mm}^{3}$ \\
\hline Glucose & $75 \mathrm{mg} / \mathrm{mL}$ & $61 \mathrm{mg} / \mathrm{mL}$ & $0 \mathrm{mg} / \mathrm{mL}$ & $66 \mathrm{mg} / \mathrm{mL}$ & $44 \mathrm{mg} / \mathrm{mL}$ \\
\hline Protein & $26 \mathrm{mg} / \mathrm{mL}$ & $22 \mathrm{mg} / \mathrm{mL}$ & $1217 \mathrm{mg} / \mathrm{mL}$ & $491 \mathrm{mg} / \mathrm{mL}$ & $1201 \mathrm{mg} / \mathrm{mL}$ \\
\hline Bacterial culture & No growth & Not available & Not available & Not available & Not available \\
\hline Fungal culture & No growth & Not available & Cryptococcus: negative & Not available & Not available \\
\hline AFB culture & No growth & Not available & Not available & Not available & Not available \\
\hline HSV Ab & Negative & Not available & Not available & Not available & Not available \\
\hline
\end{tabular}

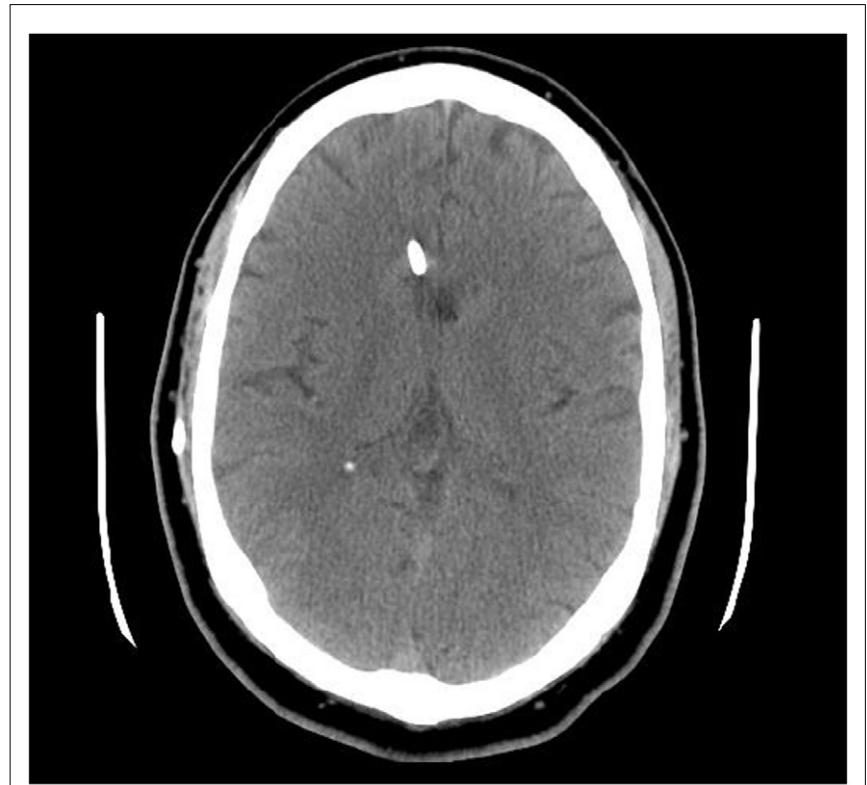

FIGURE 1 | Axial CT head, 8 months after onset of symptoms, showed a VP shunt in place.

Several days later, he was noted to have bilateral sixth and seventh cranial nerve palsies, bilateral lower extremity weakness, unsteady gait, and urinary retention. Repeat CSF analysis showed a CSF protein content of $1201 \mathrm{mg} / \mathrm{dL}$ and a CSF glucose of $44 \mathrm{mg} / \mathrm{dL}$ (Table 1).

The patient was then transferred to our institution. Upon arrival, neurologic examination was remarkable for bilateral sixth cranial nerve (CN VI) and lower motor neuron seventh cranial nerve (CN VII) palsies as well as asymmetric lower extremity paraparesis. A Foley catheter was placed. MRI of the entire neuroaxis with and without contrast showed diffuse leptomeningeal enhancement of the basal cisterns and posterior fossa, as well as leptomeningeal enhancement throughout the spinal cord with loculated fluid collection in subdural space causing distortion and compression of the spinal cord (Figures 3 and 4 ).

Because his paraparesis had progressed within hours of admission, emergent neurosurgical decompression of the spinal lesion

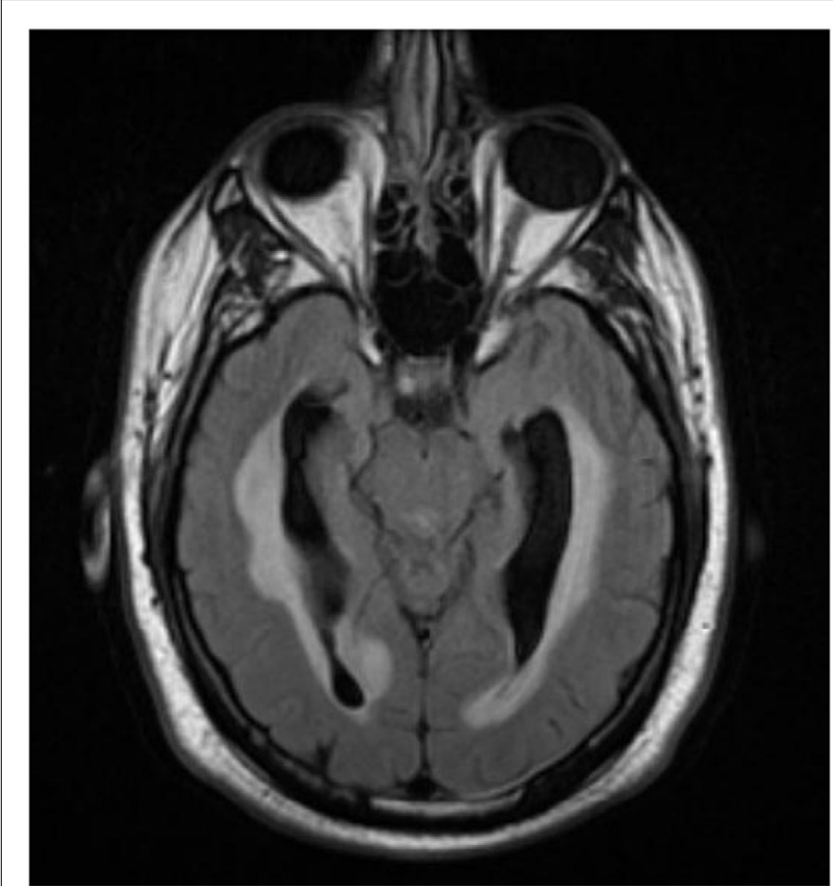

FIGURE 2 | AxialT2 FLAIR image demonstrates mild ventriculomegaly with periventricular signal abnormality consistent with acute hydrocephalus.

was undertaken. Histological analysis of the surgical specimen designated as "arachnoid and subdural material" showed portions of cartilage, soft tissue with hair follicles, a cyst lined with malignant epithelial cells consistent with a teratocarcinoma.

CT chest/abdomen/pelvis showed a $5 \mathrm{~cm}$ right kidney simple cyst. Serum alpha fetoprotein (AFP) and $\beta$-human chorionic gonadotropin ( $\beta$-HCG) were normal. A PET scan was unremarkable. Oncology and radiation therapy were consulted.

The patient developed labile blood pressure and bilateral lower extremity deep venous thrombosis, and died within days of pulmonary embolism despite therapeutic heparinization and inferior vena cava (IVC) filter placement. 
At autopsy a large thrombus was found in the right pulmonary artery. Brain examination showed the leptomeningeal involvement by a contiguous white, "icing-like" plaque. The leptomeninges at the base of the brain were filled by white-yellow, firm, granular, thickened membranes causing mass-like effect at the ventral surface of the midbrain, and pons. Examination of the spinal cord at the previous surgical site showed white plaques attached to the dura ranging in size from 0.1 to $0.2 \mathrm{~cm}$. The leptomeningeal space of the entire spinal cord was filled with dull, white, "icinglike" membrane (Figure 5). The same white-yellow membranous

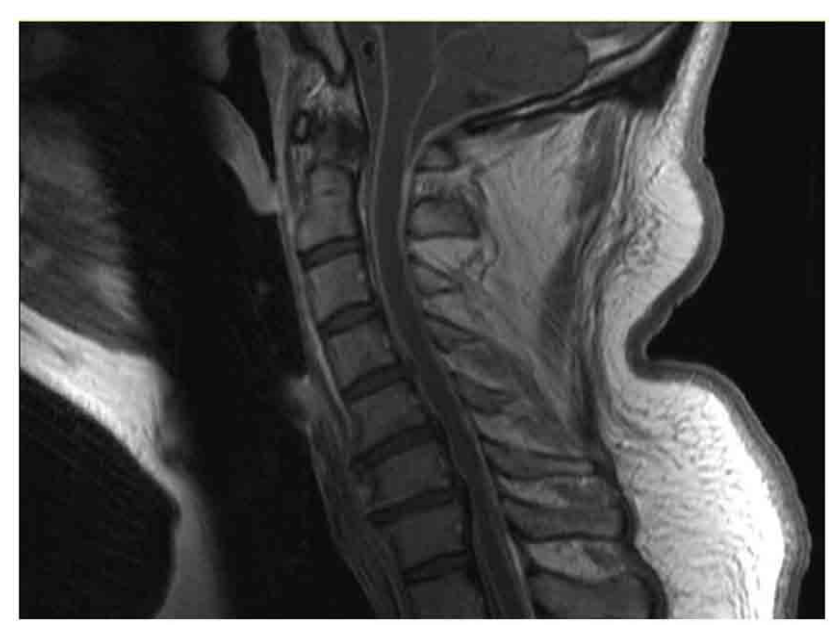

FIGURE 3 | Sagittal T1 post-contrast MRI of the cervical spine shows diffuse leptomeningeal enhancement in the posterior fossa and cervical spine.

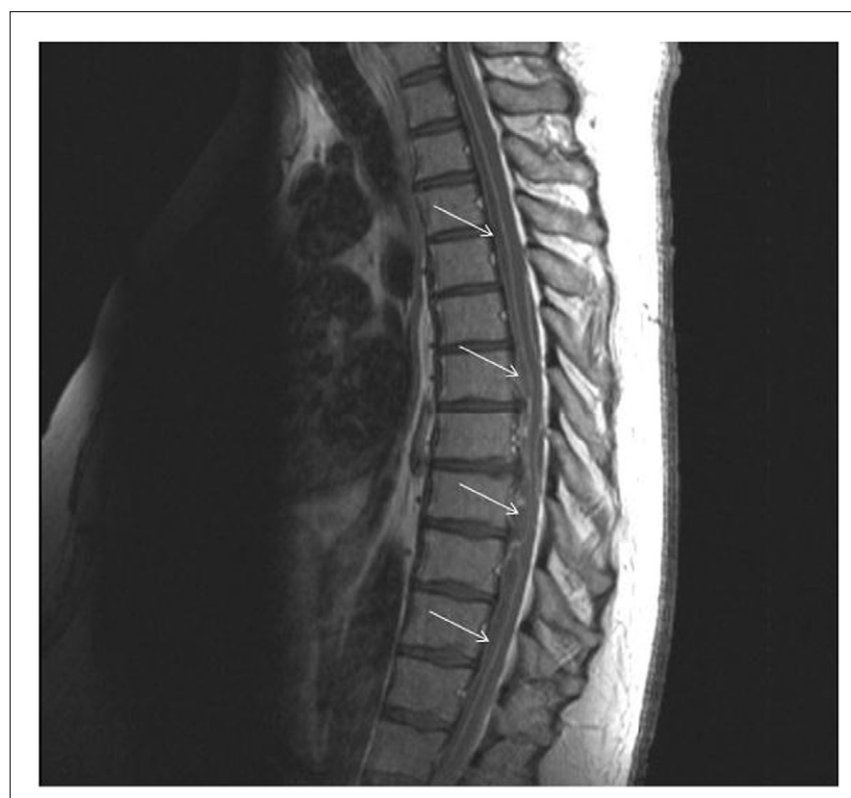

FIGURE 4 | Sagittal T1 post-contrast image of thoracic spine demonstrates loculated fluid collection in subdural space (arrows) with mass effect on the cord. structure encased the cauda equina with significant edema of the lumbar spinal cord. Immuno-histochemical analysis of the surgical specimen showed that the epithelial component was positive for pankreatin, vimentin, p63, $\beta$-HCG as well as focally for S-100 (Figure 6), and negative for TTF-1, CK7, CK20, CDX-2, AFP, and mucin.
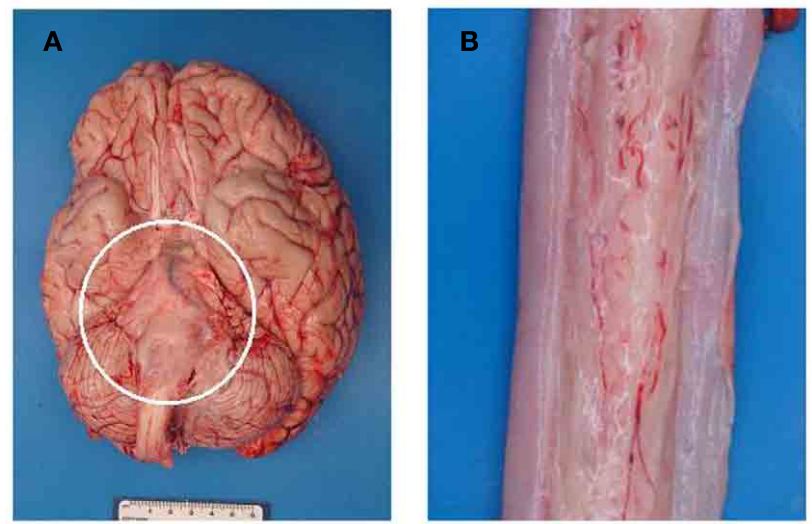

FIGURE 5 | (A) Gross photo of the base of the brain showing "icing-like" leptomeningeal thickening over the midbrain, pons, and medulla (circle). (B) Gross photo of the spinal cord with similar leptomeningeal, "icing-like" thickening over the surface of the spinal cord.
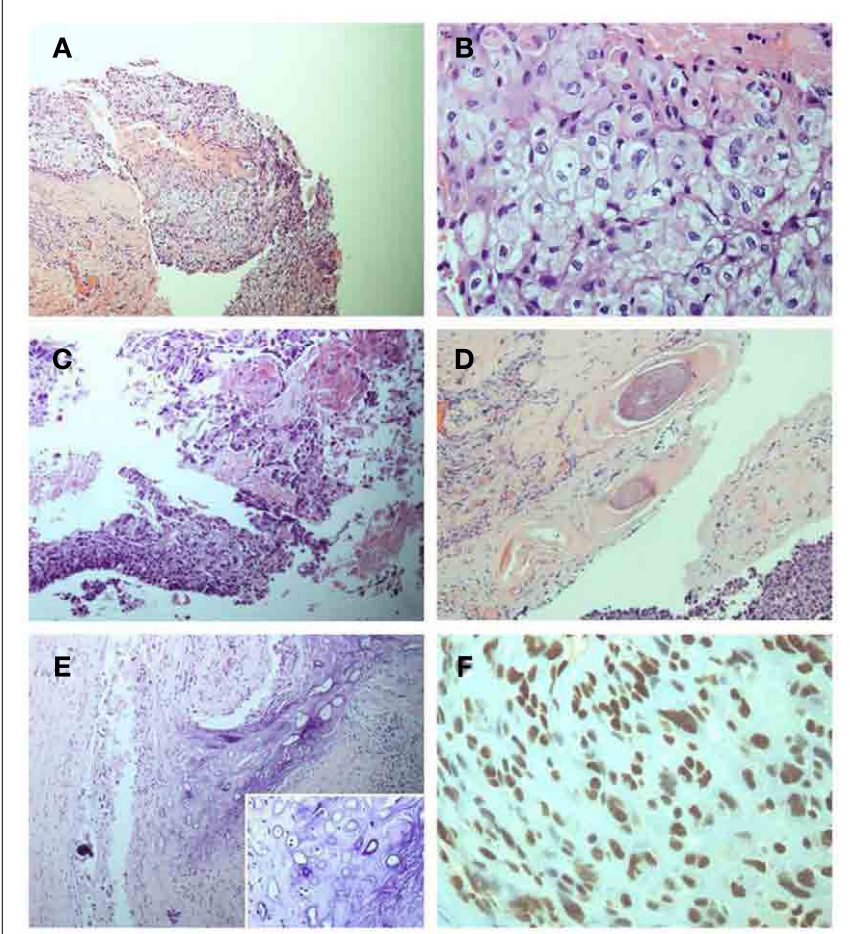

FIGURE 6 | (A) Epithelial component (low power). (B) Epithelial component (high power). (C). Epithelial component with squamous differentiation (low power). (D) Hair follicle component (low power). (E) Mesenchymal/ cartilaginous component (low power; insert: high power). (F) p63 immunoperoxidase staining of the epithelial component (high power). 


\section{DISCUSSION}

Our patient had leptomeningeal spread of a teratocarcinoma. Since no neoplasm was found outside of the cranium or spinal cord, a diagnosis of primary CNS teratocarcinoma was made. In a series of 254 teratomas from 1928 to 1982, only nine CNS teratomas were identified (excluding those involving the sacrococcygeal region). Five were intracranial and four were spinal (Tapper and Lack, 1983). Data on primary CNS teratomas at the Nizam's Institute of Medical Sciences in India showed a total of 14 teratomas; 6 were intracranial and 8 were spinal (Agrawal et al., 2010).

The origin of CNS germ cell tumors, including teratomas, is as yet unresolved. Three mechanisms have been proposed: neoplastic transformation of normal CNS germ cells, development of ectopic germ cell nests, or migration of germ cells to the CNS later in life (Love et al., 2008).

Serum AFP and $\beta$-HCG are routinely obtained in patients with suspected germ cell tumors. Marked elevation of AFP corresponds with histopathological presence of a yolk sac component within the germ cell tumor. A moderate elevation might point toward teratoma with enteric tissue component. Increased $\beta$-HCG suggests choriocarcinoma, mixed germ cell tumors, or germinomas (Hoffman et al., 1991; Love et al., 2008).

Marked elevation of the CSF protein content with decreased glucose content suggests a highly metabolic process like a neoplasm or a disseminated infection. A CSF protein content above $1000 \mathrm{mg} / \mathrm{dL}$, consistent with a Froin syndrome, suggests blockage of CSF flow.

In our patient, initial radiologic studies were unremarkable and we suspect, probably contributed to the delayed diagnosis at his local hospital. Teratomas commonly present as cystic lesions, with different tissue components including fat, soft tissue, and calcifications being radiographic hallmarks. They are usually heterogeneous on T1weighted images, with increased signal from

\section{REFERENCES}

Agrawal, M., Uppin, M. S., Patibandla, M. R., Bhattacharjee, S., Panigrahi, M. K., Saradhi, V., Rani, J. Y., Purohit, A. K., and Challa, S. (2010). Teratomas in the central nervous system: a clinico-morphological study with review of literature. Neurol. India 58, 841-846.

Bjornsson, J. M., Scheithauer, B. W., Okazaki, H., and Leech, R. W. (1985). Intracranial germ cell tumors: pathobiological and immunohistochemical aspects of 70 cases. J. Neuropathol. Exp. Neurol. $44,32-46$.

Freilich, R. J., Thompson, S. J., Walker, R. W., and Rosenblum, M. K. (1995). Adenocarcinomatous transformation of intracranial germ cell tumors. Am. J. Surg. Pathol. 19, 537-544.

Fukushima, T., Kasai, Y., Kato, K., Fujisawa, K., and Uchida, A. (2009).

fatty components and variable signal due to calcification. On T2 weighted images, soft tissue portions are isointense to hyperintense. Gradient echo signal is decreased in areas of calcification, while the soft tissue components of the teratoma enhance following contrast administration (Osborn et al., 2004; Love et al., 2008).

Definite diagnosis requires immunohistopathological analysis. A number of genetic and immuno-histochemical markers point toward immaturity of teratomas including: Sox 2 gene expression, nestin, and vimentin (Phi et al., 2007; Sakurada et al., 2008). Our patient's specimen showed tissues of all three germ cell layers and tested positive for vimentin.

Main treatment option for primary CNS teratomas consists of surgical resection (Ventureyra, 1981; Sawamura et al., 1998). In instances of mature teratomas, and in some cases of immature teratomas, complete resection is possible and curative. In cases of incomplete resection of immature teratomas, as well as in cases of teratomas with malignant transformation, radiation therapy, and chemotherapy are advised (Ling et al., 1993; Phi et al., 2005).

The prognosis of primary CNS teratomas depends on the histological type. Patients with mature teratomas have a reported survival rate $>90 \%$ after 10 years, following complete surgical resection of the tumor (Matsutani et al., 1997). Teratomas with malignant transformation carry a worse prognosis, with a reported survival rate $<10 \%$ after 1 year (Sawamura et al., 1998).

There is a reported case of malignant transformation of an intracranial large epidermoid cyst with leptomeningeal carcinomatosis (Kano et al., 2010) as well as intradural squamous cell carcinoma of the sacrum which developed into a posterior fossa "leptomeningeal carcinomatosis-like spread" (Fukushima et al., 2009). However, we are unaware of a case of leptomeningeal carcinomatosis involving the posterior fossa and spinal cord due to a primary CNS teratocarcinoma.

and pathogenesis. J. Neurosurg. 63, 155-167.

Kano, T., Ikota, H., Kobayashi, S., Iwasa, S., Kurosaki, S., and Wada, H. (2010). Malignant Transformation of an intracranial large epidermoid cyst with leptomeningeal carcinomatosis. Neurol. Med. Chir. (Tokyo) 50, 349-353.

Kumar, V., Abbas, A., and Fausto, N. (eds). (2005). "The central nervous system," in Robins and Cortran Pathologic Basis of Disease, 7th Edn, Chap. 28 (Philadelphia: Saunders), 1347-1419.

Ling, Y. J., Lai, D. M., Tsu, H. C., and Lin, S. M. (1993). Primary intracranial teratocarcinoma with extraneural metastasis - case reports and review of literature. Acta Neurol. 2, 332-337.

Love, S., Louis, D. N., and Ellison, D. W. (eds). (2008). "Tumors: non-neuroepithelial tumors and secondary effects," in Greenfield's Neuropathology, 8th Edn, Chap. 24 (London: Hodder Arnold Publishers), 2001-2182.

Matsutani, M., Sano, K., Takakura, K., Fujimaki, T., Nakamura, O., Funata, N., and Seto, T. (1997). Primary intracranial germ cell tumors: a clinical analysis of 153 histologically verified cases. J. Neurosurg. 86, 446-455.

Osborn, A. G., Blaser, S., Salzman, K. L., Katzman, G., Provenzale, J., Castillo, M., Hedlund, G., Illner, A., Harnsberger, H. R., Cooper, J., Jones, B.V., and Hamilton, B. (2004). "Teratoma," in Diagnostic Imaging: Brain, 1st Edn, Chap. 1 (Salt Lake City: Amirsys), 6-136.

Phi, J. H., Kim, S. K., and Park, H. S. (2005). Immature teratomas of the central nervous system: Is adjuvant therapy mandatory? J. Neurosurg. 103(Suppl. 6), 524-530. 
Phi, J. H., Park, S. H., Paek, S. H., Kim, S. K., Lee, Y. J., Park, C. K., Cho, B. K., Lee, D. H., and Wang, K. C. (2007). Expression of Sox2 in mature and immature teratomas of central nervous system. Mod. Pathol. 20, 742-748.

Ropper, A. H., and Samuels, M. A. (2009). "Intracranial neoplasms and paraneoplastic disorders," in Adams and Victor's Principles of Neurology, 9th Edn, Chap. 31 (New York: McGraw Hill), 612-666.

Sakurada, K., Saino, M., Mouri, W., Sato, A., Kitanaka, C., and Kayama, T. (2008). Nestin expression in central nervous system germ cell tumors. Neurosurg. Rev. 31, 173-177.

Sawamura, Y., Kato, T., Ikeda, J., Murata, J., Tada, M., and Shirato, H. (1998). Teratomas of the central nervous system: treatment considerations based on 34 cases. J. Neurosurg. 89, 728-737.

Schild, S. E., Bernd, W., Scheithauer, M. D., Haddock, M. G., Wong, W. W., Lyons, M. K., Marks, L. B., Norman, M. G., and Burger, P. C. (1996). Histologically confirmed pineal tumors and other germ cell tumors of the brain. Cancer 78, 2564-2571.

Skullerud, K., Stenwig, A. E., Brandtzaeg, P., Nesland, J. M., Kerty, E., Langmoen, I., and Saeter, G. (1995). Intracranial primary leiomyosarcoma arising in a teratoma of the pineal area. Clin. Neuropathol. 14, 245-248.

Smoker, W. R. K., Biller, J., Moore, S. A., Beck, D. W., and Hart, M. N. (1986). Intradural spinal teratoma: case report and review of the literature. Am. J. Neuroradiol. 7 , 905-910.
Suh, Y. L., Koo, H., Kim, T. S., Chi, J. G., Park, S. H., Khang, S. K., Choe, G., Lee, M. C., Hong, E. K., Sohn, Y. K., Chae, Y. S., Kim, D. S., Huh, G. Y., Lee, S. S., Lee, Y. S., and Neuropathology Study Group of the Korean Society of Pathologists. (2002). Tumors of central nervous system in Korea: a multicenter study of 3221 cases. $J$ Neurooncol. 56, 251-259.

Tapper, D., and Lack, E. E. (1983). Teratomas in infancy and childhood. A 54-year experience at the Children's Hospital Medical Center. Ann. Surg. 198, 398-410.

Ventureyra, E. C. G. (1981). Pineal region: surgical management of tumors and vascular malformations. Surg. Neurol. 16, 77-84.

Conflict of Interest Statement: The authors declare that the research was conducted in the absence of any commercial or financial relationships that could be construed as a potential conflict of interest.

Received: 04 January 2012; accepted: 19 January 2012; published online: 06 February 2012.

Citation: Vitorovic D, Rosenblum J, Thomas C, Lee J and Biller J (2012) Primary CNS teratocarcinoma. Front. Neur. 3:14. doi: 10.3389/fneur.2012.00014

This article was submitted to Frontiers in Neurology Education, a specialty of Frontiers in Neurology.

Copyright () 2012 Vitorovic, Rosenblum, Thomas, Lee and Biller. This is an open-access article distributed under the terms of the Creative Commons Attribution Non Commercial License, which permits non-commercial use, distribution and reproduction in other forums, provided the original authors and source are credited. 